\title{
Marine zooplankton retrieval system design and Application in China
}

\author{
Sun Xiaohong ${ }^{1 \mathrm{a}}$ Li Changping $^{2 \mathrm{~b}}$ Wanglongxiang $^{1 \mathrm{c}} \mathrm{He}_{\mathrm{Hong}}{ }^{{ }^{1 \mathrm{~d}}} \mathrm{Li} \mathrm{jie}^{3 \mathrm{e}}$ \\ ${ }^{1}$ Shandong University at Weihai, Weihai, China \\ ${ }^{2}$ Information Center at Weihai, China \\ ${ }^{3}$ School of Environmental and Municipal Engineering, Qingdao Technological University \\ asunxiaohongsd@163.com, bsdppc-lcp@163.com, wlxsxh220@163.com, dhehong@sdu.edu.cn, \\ jjli2001@sina.cn
}

Keywords: zooplankton, classification, retrieval system, database

\begin{abstract}
Zooplankton plays an important role in the marine system, so it becomes important to investigate the background information and to archive the data, as well as to analyse the corresponding parameters. As marine zooplankton species belong to various categories and morphologies, identification is difficult and requiring professional staff. Till now, database of species composition and distribution in zooplankton have not been designed in China, but these databases are so important to provide some references for the study of zooplankton.Based on the necessary of the zooplankton database, this study developed a set of software which contained zooplankton species (including taxonomy, image and size), quantity (number, biomass), temporal and spatial distribution and environmental factors (temperature, salinity, chlorophyll). The software contains parameter refering and comparative analysing, and also can facilitate the researcher to archive, analyse and share zooplankton data.This study adopted B/S structure and used Java and mysql technology, combining with struts hibernate to develop. This system manages the zooplankton data and uses line charts (jfreechart) to analyse sorts of factors and results. This system also includes background for managers to add, edit, and delete data for facilitating system extension.
\end{abstract}

\section{Introduction}

zooplankton is quite complex in the class composition, including protozoa, Coelenterata, ,Ctenophora, Phylum Arthropoda, Phylum Mollusca, Chaetognatha, in addition, planktonic animal taxa also contains many stages of plankton, mainly each stage of the planktonic larvae of benthic animal and swimming animal (fish, cephalopods), juvenile, etc. Zooplankton distributes from the ocean surface to hundreds of meters of water even in thousands of meters deep, they not only control of oceanic primary production (phytoplankton), but also are food foundation of aquatic animal in the upper marine food chain, especially of the small fish and fish larvae, so it is a very important significance in marine fishery production ${ }^{[1]}$.With the marine ecological environment deterioration and resource destruction according to the development of economy and the intensification of human activities, structure and function of ecosystem has changed a lot. In order to achieve the sustainable use of resources, protection of biological diversity, natural disaster prevention and control of marine pollution, investigation is particularly important for the zooplankton data and background, especially in data archiving management as well as the comparative analysis of corresponding parameters ${ }^{[2-3]}$.

Because of the complex categories, types and forms, identification is so difficult and requires staff having considerable taxonomic expertise based on the microscope identification. Combining the high intensity and low efficiency in classification work, the cross research in this field and other fields has been very difficult. Zooplankton classification and counting are so great significant for the understanding of its position and role in the partical cycle and energy flow of the marine ecosystem. Furthermore, analyzing in relationship between zooplankton variation and related environmental factors can provide the basis for the study of global climate change. Therefore, a long time series of variation in zooplankton quantity,species, spatial change and driving factor is necessary for zooplankton research and other interdisciplinary research. However, due to the 
domestic research in zooplankton ecological distribution started later, classification and counting are all worked with manual operation, and also due to the disparity of the professional level in the classification and counting, error rate is very high. So digitization in zooplankton classification and counting has a very important significance on subsequent zooplankton ecology research ${ }^{[4]}$.

Internationally, database related to zooplankton categories and the distribution have been some developed countries [5], offered reference data for the planktonic animal research, but these databases lack of comparative analysis of relationship between different parameters.In addition, due to the differences in geographical location, composition, number and size, researchers need a database of zooplankton daita for comparative analysis. However, design and development work of domestic zooplankton database has not professional, uniform version, and preservation relevant data only stay in excel form , so consulting and parameters analysis is quite troublesome, and the data can not be shared, causing a great waste of resources. A zooplankton database is established based on the necessity in research, in cluding zooplankton species (classification, image, size), quantity (number, biomass), temporal and spatial distribution and environmental factors (temperature, salinity distribution area, chlorophyll), which is a comprehensive software in inquiry, comparison and analysis of different parameters, in order to facilitate the zooplankton research in data archiving management, analysis and sharing.

\section{Structure and function design of the system}

\section{Structure and function}

Zooplankton include various kind and describing is differences for different class , therefore, this system set the door, classes, orders, families, genera, species of sub library, including Chinese name and Latin name, according to the classification characteristics of different taxa. In addition, this system also set the nodules in temperature, salinity, chlorophyll, biomass and dominance for environmental characteristic query in relevant waters, and according to the statement analysis module, data can be analyzed and compared between the various factors.

\section{User interface}

The system has good customer interface for using ordinary WWW browser to query, and all the inquiring parameters are displayed on the main page (Fig.1).

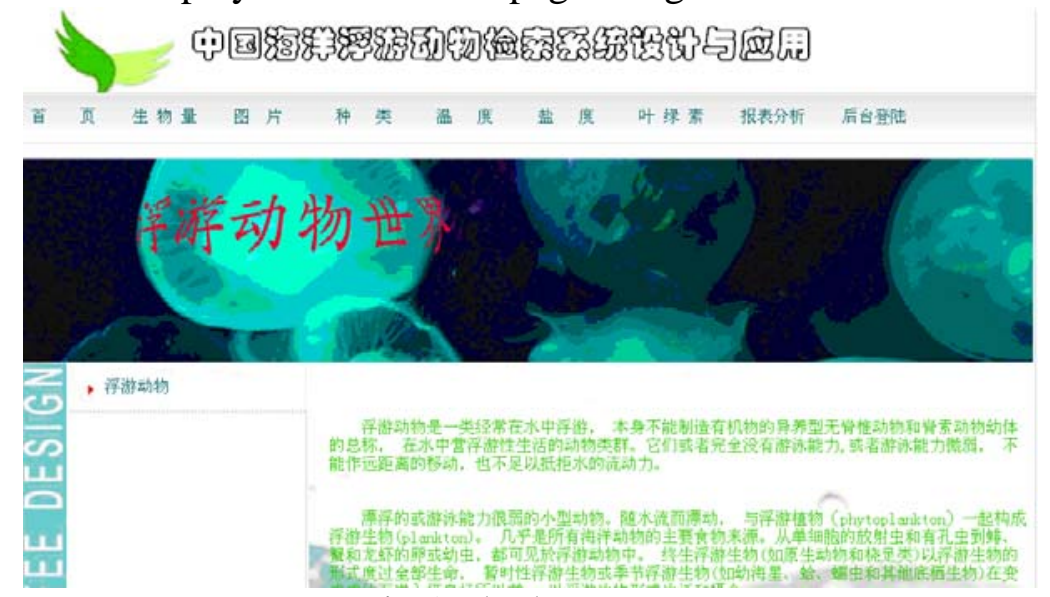

Fig.1 The homepage

Clicking on each module, Information can all be inquried according to the prompt, and the result was illustrated under the inquiry form. All the inquiry page was displayed in selection box, to avoid the system collapse as the users' improper inputing.

In the picture module for example, user can only input into Chinese or Latin name, or both to inquiry (Fig. 2), and clicking on the submit, subsequent page shows the picture of inquring species (Fig, 3). 


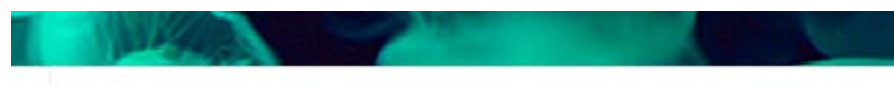

图片〉查看图片

只需输入中文名和拉丁名中的一个

中文名:

拉丁名: 提交

Fig.2 Image inquiry page

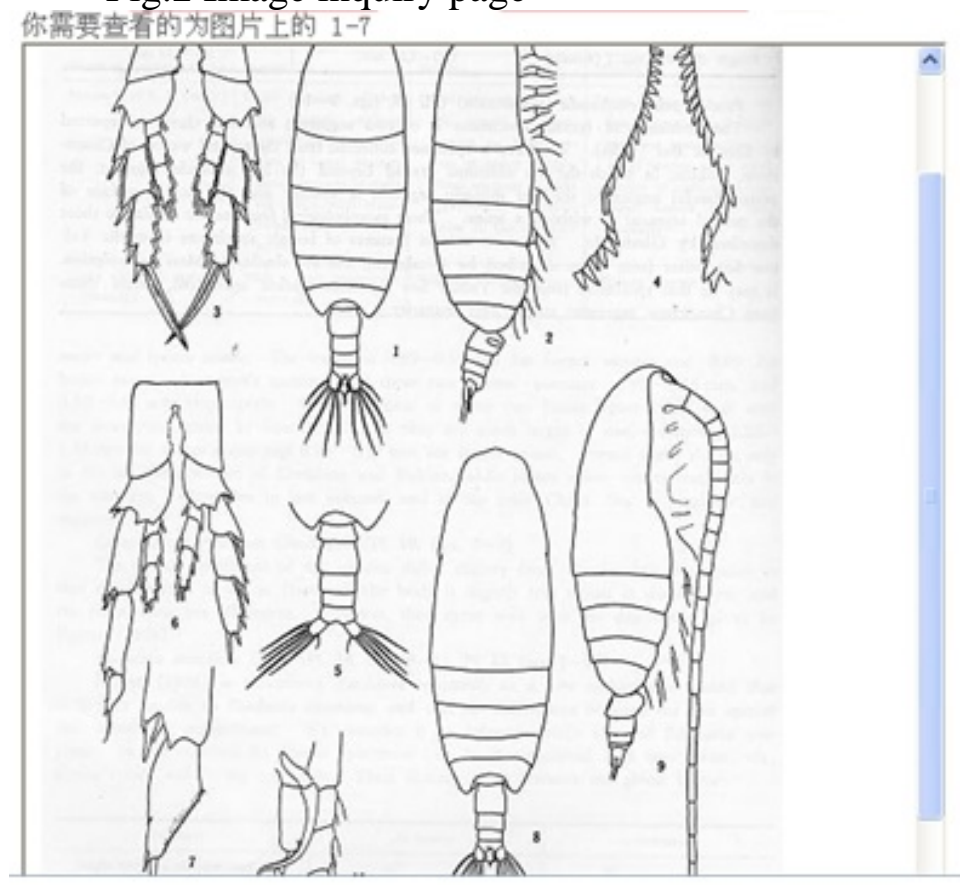

Fig. 3 Image inquiry results

The environment factor inquiry in this system was divided into the year and month modules. Users can directly query all the months data in a year, or can also directly query a data in one month according to need. Taking the inquiry in temperature as an example, in the marquee of the year,user selects "2005" in the year box, and then select "all " in the month box(Fig. 4), clicking the enter, the page displays all the temperature data in 2005 submitted (Fig. 5).

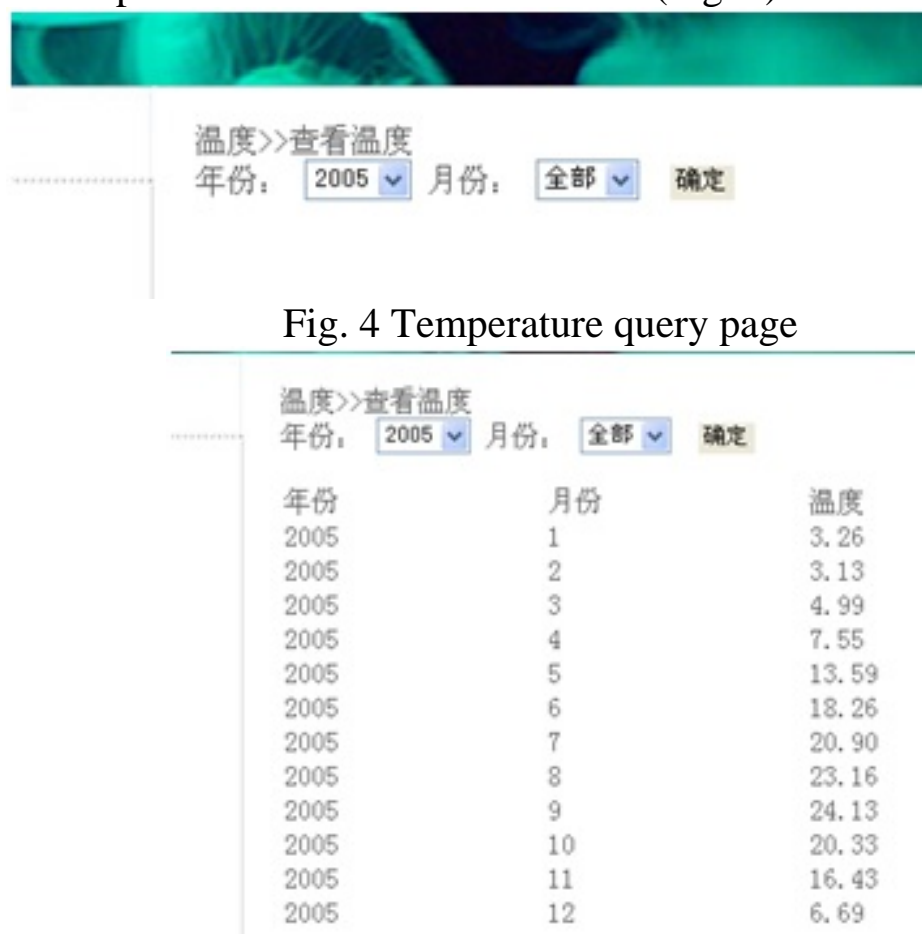

Fig. 5 Temperature query results

The system is particularly added the statement analysis module, the related factors were displayed or cross contrasted in visual chart display. At present, the system can display and analysis of six 
common factors in single line graph, in addition, also carried out cross analysis in double line chart. Factors will be added based on demand in the future (Fig. 6). Taking the analysis of number of categories and temperatures in 2005 as an example, Fig. 7 shows the double line chart of the two factors.
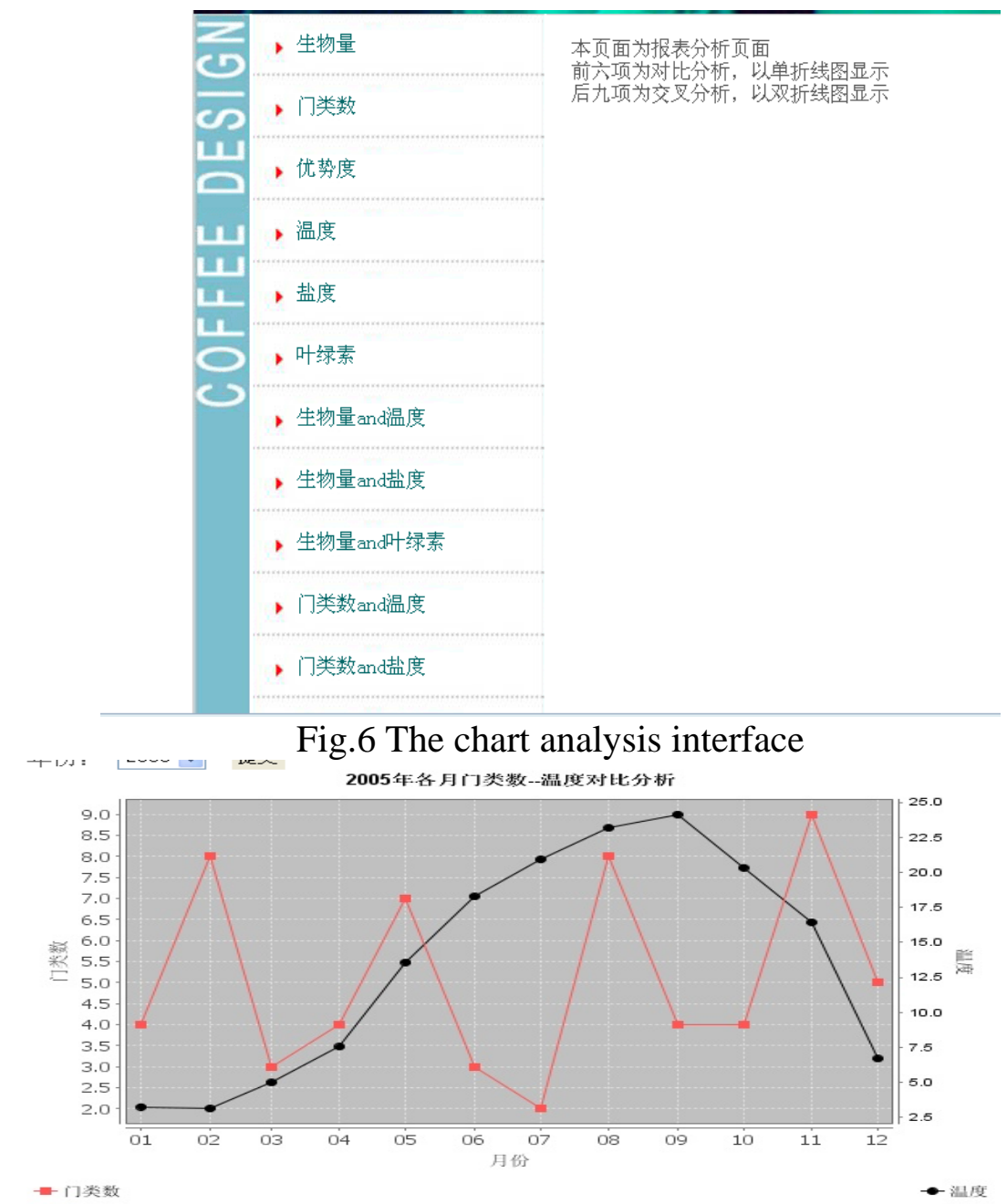

Fig. 7 Categories - temperature chart

\section{The administrator module}

The system is arranged the librarian page, who can enter and modify the parameters relating to the system (Fig. 8).

\section{浮 游 信 息网 站 后台管 理}

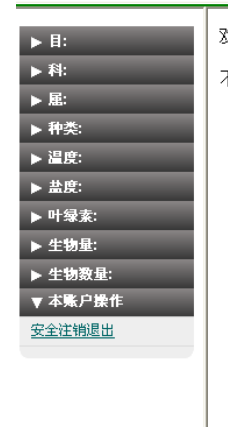

欢迎来到浮游信息网站后台管理界面, 本管理界面具有查看, 修改, 增加, 删除等功能

不建议使用删除功能, 本系统删除功能为彻底删除, 不可恢复, 本系统所有删除可以用修改替换

Fig. 8 Background management page

In the genus module as an example, managers can view all genera and can increase the genus after entering, and also can edit the existing genera (Fig. 9, fig. 10) 


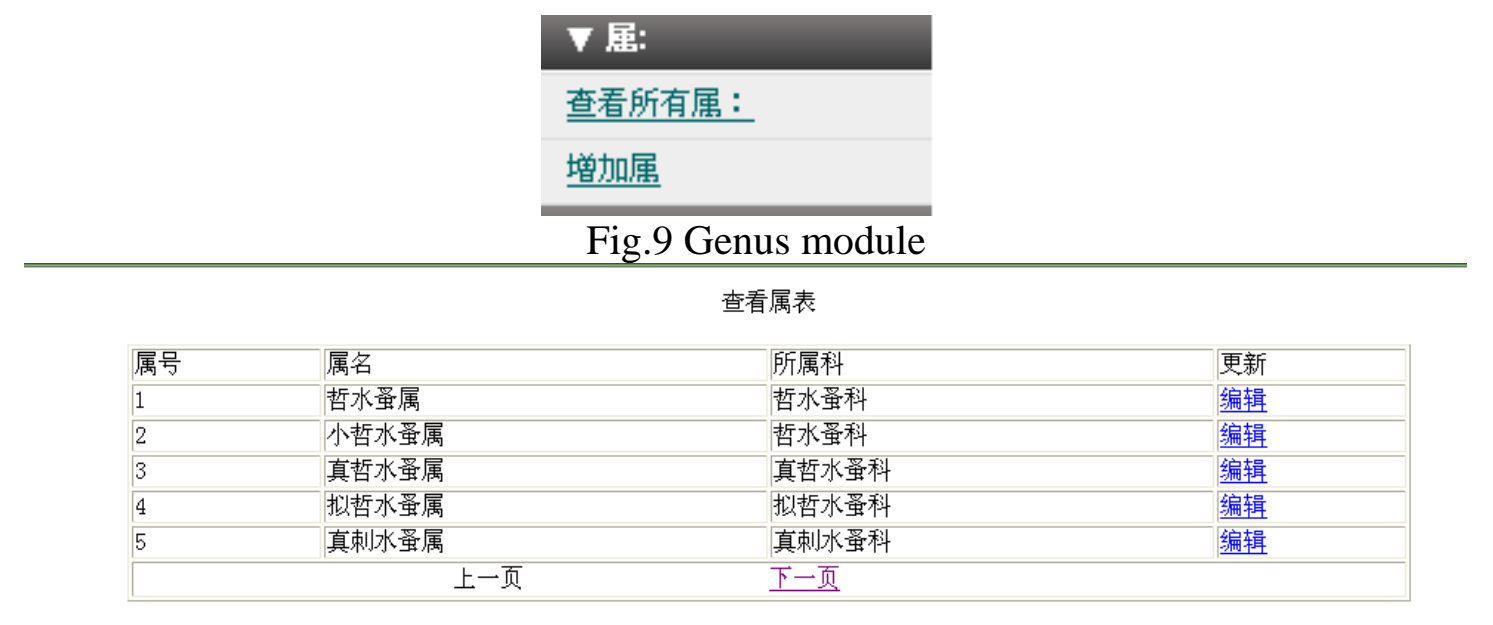

Fig.10 View all the information for genus

\section{Discussion}

Design of this zooplankton retrieval system database is to better serve domestic planktonic animal workers to study and exchange, realizing the data sharing, and the contrast analysis function can help for comparison of parameters in each area, so that a more in-depth understanding of the ecological distribution of marine zooplankton. "Marine Planktonic Copepods" [5] query system is currently the most widely used and the most comprehensive information system. This system can query the zooplankton species area around the world, premising that the related research workers enter this sharing information in relavant area; However, design and development work of domestic zooplankton database has not professional and uniform version, A similar zooplankton information platform was first designed by Institute of Oceanology, Chines Academy of Sciences ${ }^{[6]}$, mainly relating to zooplankton species and classification information, however, no information about the number and distribution of zooplankton , and also the analysis of relationship with environmental factors . The marine biological germplasm resources in South China Sea database ${ }^{[7]}$, which was desiged by Development of South China Sea Fisheries Research, China Aquatic Science Research Institute, include resource query but also confined to the main parameters of various marine organisms and classification information, no comparison and analysis function between various parameters. Therefore, the development of a relatively professional, setting various functions, and confining to zooplankton system is necessary for the study of marine ecosystems, which will greatly promotes the research process of zooplankton in related field.

The design and application of Marine zooplankton retrieval system in china can be said to be a major improvement of the existing planktonic animal database in international. But this database is still in the early establishment, poorly in species and numbers, and need to constantly improve and filling. with the users' application and information sharing, this phenomenon will be improved.

\section{Conclusion}

1) A professional,marine zooplankton database was established for researchers in different background, wich facilitate the users in classification, identification, query image control and data sharing of common zooplankton.

2) Realized the comparative analysis of the main parameters such as composition, quantity variation (number, biomass) and seasonal variation in different area of our country.

3) The system is open to all applicants, and enable the background management for part of professional applicants wich can input and edit some related data. 


\section{References}

[1]Li zheng. Application of optical Plankton Counter -OPC and image analysis technique in the analysis of zooplankton samples.2009:11-14.

[2]Davis CS, Gallager SM, Berman MS, Haury LR, Strickler JR.The video plankton recorder(VPR): design and initial results. Archiv fur Hydrobiologie-Beiheft Ergebnisse der Limnologie. vol.36(1992). p.67-81.

[3]Davis CS, Gallager SM, and Solow AR. Microaggregations of oceanic plankton observed by towed video microscopy. Science, vol.257(1992). p.230-232.

[4]Davis CS, Gallager SM, Marra M, and Stiwart WK.Rapid visualization of plankton abundance and taxonomic composition using the Video Plankton Recorder. Deep Sea Research Part II. vol.43(1996).p.1947-1970.

[5] Marine Planktonic Copepods, http://copepodes.obs-banyuls.fr/en/Searching.php.

[6]Zooplankton information platform:http://210.72.157.135/Default.aspx?tabid $=36 \&$ Language $=\mathrm{zh}-\mathrm{CN}$, Institute of oceanology.

[7]The South China Sea marine biological Germplasm Resources Database, http://www.scsagr.com/resource-info.asp?id=f08414193231. 